${ }^{1}$ Department of Pediatrics, Diabetology, Endocrinology and Nephrology, Medical University of Lodz, Poland

${ }^{2}$ Department of Diabetology and Metabolic Diseases, Medical University of Lodz, Poland

${ }^{3}$ Profil Institut für Stoffwechselforschung GmbH, Neuss, Germany

${ }^{4}$ Department of Pediatrics, Oncology and Hematology, Medical University of Lodz, Poland

${ }^{5}$ EIT Health InnoStars North Eastern Europe, Budapest, Hungary

\title{
Pains and needs of patients with type 2 diabetes as targets for novel technologies
}

\section{ABSTRACT}

Background. As diabetes affects multiple spheres of life the aim of this study was to explore the pain points of diabetes management as perceived by persons with type 2 diabetes and to identify their expectations towards new technologies.

Methods. Patients with type 2 diabetes treated with oral hypoglycemic agents and/or insulin were surveyed. Respondents were asked to rate (i) the impact of diabetes on their daily life and (ii) their needs for improvements in different aspects of diabetes management on a five level Likert-type scale.

Results. One hundred and fifty-four persons with type 2 diabetes were included. Most frequently reported challenges were: fear of diabetes complications development or progression ( $98.7 \%$ of patients), presence of diabetes complications $(65.6 \%)$, frequent hyperglycemia (53.2\%), and diabetes limiting one's daily activities (50\%). Most frequently expressed needs were: to evaluate glucose concentrations without finger pricking $(98.1 \%)$, contact with a physician using mobile solutions and/or telemedicine $(98.1 \%)$, and automation of insulin dosing (91.6\%) and of calories/

Address for correspondence: Beata Mianowska, MD, PhD Department of Pediatrics, Diabetology Endocrinology and Nephrology Medical University of Lodz, Poland Sporna 36/50, 91-738 Lodz Phone: 48426177 750; fax: 48426177798

e-mail: beata.mianowska@umed.lodz.pl

Clinical Diabetology 2020, 9; 6: 400-410

DOI: $10.5603 /$ DK.2020.0052

Received: 07.05.2020

Accepted: 01.11.2020 /carbohydrates' evaluation in meals (84.4\%). Needs for telemedicine development, automation of insulin dosing and that the others help patients with diabetes management were more frequently reported by persons with: higher $\mathrm{HbA}_{1 \mathrm{c}}$, positive severe hypoglycemia history, concomitant chronic complications or diseases, and by those who were on insulin therapy.

Conclusions. Although many diabetes technologies which meet the needs of patients with type 2 diabetes are already available, the study uncovers a high requirement for integrating them into disease management. The challenge pertains to implementation of the right technological solutions fulfilling needs of particular groups of patients and to helping them to embrace novelties into their daily lives. (Clin Diabetol 2020; 9; 6: 400-410)

Key words: digital health, eHealth, patients, telemedicine, type 2 diabetes, artificial pancreas

\section{Introduction}

Diabetes affects more than 400 million people worldwide and significantly affects their and their families' quality of life, especially when accompanied by chronic complications [1, 2]. It is not clear whether and which diabetes-related inconveniences are perceived by patients as mostly affecting their daily life. Discrepancies have been identified between the fields that persons with diabetes and their relatives would prioritize and the scientific activities in diabetology $[3,4]$. The importance of a participative approach involving patients in the design and implementation of health innovation is increasingly recognized [5]. 
Over the last years multiple digital i.e. electronic health (eHealth) technologies aimed at improvement of diabetes patients' quality of live and glycemic control have been developed [6]. Such solutions include: (i) mobile health (mHealth), e.g. text messaging, smartphone applications (e.g. "apps" helping to count calories/ carbohydrates content in meals or replacing diabetes management log-books), and wearable technologies enabling glucose levels assessment without finger pricking, i.e. real-time continuous glucose monitoring (rtCGM) systems and intermittently scanned CGM (iCGM)), (ii) telemedicine technologies (e.g. enabling remote contact with care providers for a discussion of electronically submitted CGM profiles), (iii) new specialized devices - from insulin pens memorizing insulin doses to automated insulin delivery (artificial pancreas) systems closing the loop between CGM assessments and a continuous subcutaneous insulin infusion (CSII) [7-11].

Although most new technological solutions are initially used by persons with type 1 diabetes, they may add value also to a more personalized and costeffective management of persons with type 2 diabetes [10]. For instance, $\mathrm{HbA}_{1 \mathrm{c}}$ levels decreased significantly in patients with type 2 diabetes who used rtCGM and were on insulin pump therapy, and feasibility and safety of using insulin pump therapy and a fully automated insulin delivery system was shown for persons with type 2 diabetes [12-14].

As patient's perception might add valuable input to the enhancement of existing and the development of new diabetes technologies, the objective of this study was to identify the pain points in diabetes management that are still experienced by persons with type 2 diabetes in the era of digital health implementation and to identify their expectations towards new technologies.

\section{Methods}

This was a cross-sectional, questionnaire-based study. The study was carried out in one hospital diabetes department and in one local diabetes outpatient clinic; data were collected between June 2017 and March 2018. Inclusion criteria were: age from 18 up to 90 years, type 2 diabetes duration 6 months or more, treatment with oral hypoglycemic agents and/or insulin injections. Patients with type 2 diabetes treated only with diet and lifestyle modification were excluded. Glycated hemoglobin $\left(\mathrm{HbA}_{1 \mathrm{c}}\right)$ levels, body mass and height were collected from patients' medical documentation. The included patients had previously received basic education (lasting up to 45-90 minutes) in diabetes management (i.e. about nutrition, self-monitoring of blood glucose, and for patients treated with insulin - about insulin action and injection technique) provided by their physicians and/or nurses trained in diabetes care. None of patients used CGM or insulin pump.

The questionnaire developed for the purpose of this survey included questions grouped into following categories: A - demographic and medical care related data, B - impact of diabetes on daily life, and C new technologies and "my diabetes", i.e. how new technological solutions could help participants in their diabetes management and in their everyday live. In part $B$ respondents were asked to rate the importance of problems concerning diabetes on a five level Likert-type scale ( 1 - definitely not a problem, 2 - rather not a problem, 3 - moderate problem, 4 - big problem, 5 - huge problem). Answers were further grouped as indicating a nonsignificant (scores 1 and 2) or significant (scores $3,4,5$ ) problem. In part $C$ patients rated their need for improvements in diabetes management (including introduction of existing and emerging new technological solutions) on five level Likert-type scale (1 - no need, 2 - little need, 3 - moderate need, 4 - big need, 5 - huge need), and again answers were further grouped as indicating nonsignificant (scores 1 and 2) or significant (scores 3, 4, 5) need for improvement. The questionnaire is freely available online at the following link: https://dochub.com/anetagruchala /7J4mQvgRvJYmIQ0Rj2pO5n/questionnaire-assessingpains-and-needs-of-persons-with-type-2-diabetesonline-pd? $d t=y V f o 6 w P a s A g D D H f L q 95 b$. Participants answered the questions in the presence of one of the investigators (AG), as some of them needed assistance with reading or writing due to their disabilities.

The study protocol was approved by the ethics committee of the Medical University of Lodz, Poland (RNN/197/17/KE). Written informed consent was obtained from each participant, and filled questionnaires were fully anonymous.

Statistical analysis was performed with Statistica version 13.1 software. Chi-square and Fisher exact tests were used for the analysis of frequency of answers (ranging particular issues as a significant problem/ /need vs. a nonsignificant problem/need) stratified according to patients' clinical characteristics. In all cases, the results were considered statistically significant at $P<0.05$. In the analyses of the impact of diabetes duration on patients' answers Pearson Chi-square test was used to compare the frequency of answers between patients with diabetes duration below or equal to the median diabetes duration for the total group $(\leq 12$ years) versus patients with diabetes duration above the median (> 12 years). Moreover, associations between diabetes duration and patients' answers to particular questions considered as continuous variables (answers 
Table 1. Characteristics of the study group ( $n=154,69$ men and 85 women)

\begin{tabular}{lc}
\hline Characteristics & Mean \pm standard deviation or number (percentage) \\
\hline Age (years) & $65.6 \pm 8.3$ \\
Diabetes duration (years) & $14.4 \pm 9.5$ \\
$\mathrm{BMI}\left[\mathrm{kg} / \mathrm{m}^{2}\right]$ & $30.4 \pm 3.7$ \\
$\mathrm{HbA}_{1 \mathrm{c}}(\%)$ & $9.0 \pm 1.7$ \\
$\mathrm{HbA}_{1 \mathrm{c}}[\mathrm{mmol} / \mathrm{mol}]$ & $75 \pm 10.7$ \\
Diabetes medication & $129(83.8 \%)-$ insulin therapy with or without oral hypoglycemic agents \\
& $25(16.2 \%)$ oral hypoglycaemic agents (without insulin) \\
Professional activity & 50 (32.5\%) - professionally active \\
& $35(22.7 \%)-$ disabled \\
Presence of chronic diabetes complications & $69(44.8 \%)-$ retired \\
Positive history of severe hypoglycemia & $102(66.2 \%)$ \\
Presence of at least one concomitant chronic disease & $34(22.1 \%)$ \\
\hline
\end{tabular}

from 1 to 5) were analyzed; associations with Spearman's rank correlation coefficient $\rho \geq 0.4$ at $\mathrm{P}<0.05$ were regarded clinically significant.

\section{Results}

One hundred and eighty-nine patients (18-90 years, type 2 diabetes) were offered the possibility to participate in the study. Nineteen patients refused to participate. Sixteen patients who primarily agreed were excluded due to non-conformity with the protocol (too short diabetes duration, not treated with insulin or oral hypoglycemic medications at the time of survey). One hundred and fifty-four patients with type 2 diabetes (85 women and 69 men; aged from 46 to 80 years, with diabetes duration from 1 to 39 years; 112 surveyed in a hospital, 42 surveyed in an outpatient clinic) were included into the final analysis. Characteristics of the study group are presented in Table 1.

\section{Diabetes-related problems}

Problems most frequently rated by participants as significant were: fear of development or progression of chronic diabetes complications (graded as significant by $98.7 \%$ of patients), presence of chronic diabetes complications (65.6\%), frequent hyperglycemia (53.2\%), diabetes as a factor limiting one's daily activities (50\%) (Table 2 ).

In order to assess whether the clinical characteristics of patients determine types of problems reported by them, subgroups of participants were compared depending on $\mathrm{HbA}_{1 \mathrm{c}}$ (below and above the median, i.e. $8.7 \%$ ), history of severe hypoglycemia (no such episode vs. at least one severe hypoglycemia with loss of consciousness, seizure or coma), presence of chronic diabetes complications (no vs. yes), presence of one or more chronic concomitant diseases (no vs. yes), and treatment with insulin (no vs. yes) (Table 3). Limitation of daily activity related to diabetes was significantly higher in patients: with $\mathrm{HbA}_{1 \mathrm{c}}$ above median $(65.8 \%$ vs. $34.6 \%, \mathrm{P}<0.001)$, with a history of severe hypoglycemia $(88.2 \%$ vs. $39.2 \%, \mathrm{P}<0.001)$, with chronic diabetes complications $(65.7 \%$ vs. $19.2 \%, \mathrm{P}<0.001)$ and on insulin therapy $(57.4 \%$ vs. $12.0 \%, \mathrm{P}<0.001)$. Fear of hypoglycemia and hypoglycemia occurrence were more frequently reported as a problem by persons with a history of severe hypoglycemia, by persons with chronic complications and by those treated with insulin. Patients with diabetes duration longer than median for the total group (over 12 years) claimed significantly more frequently $(P<0.05)$ compared to patients with shorter diabetes duration that the following issues posed a significant problem for them: diabetes limiting daily activities $74 \%$ vs. $34 \%$, necessity to prick fingers $78 \%$ vs. $42 \%$, frequent hypoglycemia episodes $78 \%$ vs. $46 \%$, low blood glucose levels at night $79 \%$ vs. $47 \%$, fear of hyperglycemia $77 \%$ vs. $42 \%$, presence of chronic diabetes complications $73 \%$ vs. $17 \%$, dependence on family members' help $76 \%$ vs. $34 \%$, costs of diabetes complications therapy being a burden $74 \%$ vs. $15 \%$. Moreover, there was a positive correlation $(P<0.05)$ between longer diabetes duration and fear of chronic diabetes complications $(\rho=0.57)$, diabetes limiting patient's daily activities $(\rho=0.43)$, dependence on family members' help $(\rho=0.46)$, and costs for diabetes complications therapy being perceived as a burden $(\rho=0.43)$.

\section{Diabetes-related needs}

Almost a half of the participants (46.8\%) indicated that they were dependent on help of a family member 
Table 2. Percentage of participants who rated potential problems related to their diabetes and its management as non-significant and significant. Respondents rated the importance of problems on a five level Likert-type scale: 1 - definitely not a problem, 2 - rather not a problem, 3 - moderate problem, $4-$ big problem, 5 - huge problem, and answers were further grouped as indicating a nonsignificant (scores 1 and 2 ) or significant (scores 3, 4, 5) problem. Problems rated as significant by the highest percentage of participants are listed first

\begin{tabular}{|c|c|c|c|}
\hline $\begin{array}{l}\text { Problem related to diabetes } \\
\text { and its management }\end{array}$ & $\begin{array}{l}\text { Participants who rated } \\
\text { a problem as significant (\%) }\end{array}$ & $\begin{array}{l}\text { Participants who rated a problem } \\
\text { as non-significant (\%) }\end{array}$ & $\begin{array}{l}\text { Total number } \\
\text { of answers }\end{array}$ \\
\hline $\begin{array}{l}\text { Fear of chronic complications of diabetes - } \\
\text { problems with eyes, kidney, heart, atherosclerosis, } \\
\text { diabetic foot, amputation etc. }\end{array}$ & 98.7 & 1.3 & 154 \\
\hline $\begin{array}{l}\text { Presence of chronic diabetes complications - } \\
\text { problems with eyes, kidney, heart, atherosclerosis, } \\
\text { diabetic foot, amputation etc. }\end{array}$ & 65.6 & 34.4 & 154 \\
\hline High blood glucose levels (often occurring) & 53.2 & 46.8 & 154 \\
\hline Limitation of daily activity caused by diabetes & 50.0 & 50.0 & 154 \\
\hline $\begin{array}{l}\text { Necessity to check blood glucose level with } \\
\text { blood glucose meter - pricking fingers }\end{array}$ & 39.0 & 61.0 & 154 \\
\hline Fear of hypoglycemia & 34.4 & 65.6 & 154 \\
\hline Lack of freedom concerning meals & 31.2 & 68.8 & 154 \\
\hline Low blood glucose levels (often occurring) & 26.0 & 74.0 & 154 \\
\hline Estimation of calories or carbohydrates in meals & 23.4 & 76.6 & 154 \\
\hline Insufficient knowledge about diabetes & 23.4 & 76.6 & 154 \\
\hline Low blood glucose levels at night & 22.1 & 77.9 & 154 \\
\hline $\begin{array}{l}\text { Feeling uncomfortable or ashamed while per- } \\
\text { forming activities related to diabetes manage- } \\
\text { ment (checking blood glucose levels, injecting } \\
\text { insulin) in presence of other people }\end{array}$ & 20.1 & 79.9 & 154 \\
\hline Lack of freedom in physical activities & 16.9 & 83.1 & 154 \\
\hline $\begin{array}{l}\text { Necessity to check blood glucose level with } \\
\text { blood glucose meter - remembering to do it }\end{array}$ & 14.3 & 85.7 & 154 \\
\hline $\begin{array}{l}\text { Necessity to inject insulin - counting insulin } \\
\text { doses }\end{array}$ & 5.4 & 94.6 & 129 \\
\hline $\begin{array}{l}\text { Necessity to inject insulin - technique of the } \\
\text { injection (pushing the plunger etc.) }\end{array}$ & 3.1 & 96.9 & 129 \\
\hline $\begin{array}{l}\text { Necessity to check blood glucose level with } \\
\text { blood glucose meter - recording results } \\
\text { in a log-book }\end{array}$ & 2.6 & 97.4 & 154 \\
\hline $\begin{array}{l}\text { Necessity to inject insulin - setting the insulin } \\
\text { dose on the pen injector }\end{array}$ & 2.3 & 97.7 & 129 \\
\hline Necessity to take oral diabetes medication & 1.8 & 98.2 & 113 \\
\hline Necessity to inject insulin — pain during injection & 0.8 & 99.2 & 129 \\
\hline $\begin{array}{l}\text { Necessity to check blood glucose level with } \\
\text { blood glucose meter - operating blood } \\
\text { glucose meter }\end{array}$ & 0.7 & 99.3 & 154 \\
\hline
\end{tabular}

in their diabetes management. More than one quarter (28.6\%) would like to have a nurse/non-family caregiver support in diabetes management at home.

Detailed results of patients' perception of needs for improvement in diabetes management expressed as percentages of answers indicating significant need and non-significant need are presented in Table 4. The most frequently reported significant needs were: to evaluate glucose concentrations without finger pricking ( $98 \%$ of patients) and to have contact with a physician using mobile solutions and/or telemedicine to share data including doses of insulin, blood glucose levels, 


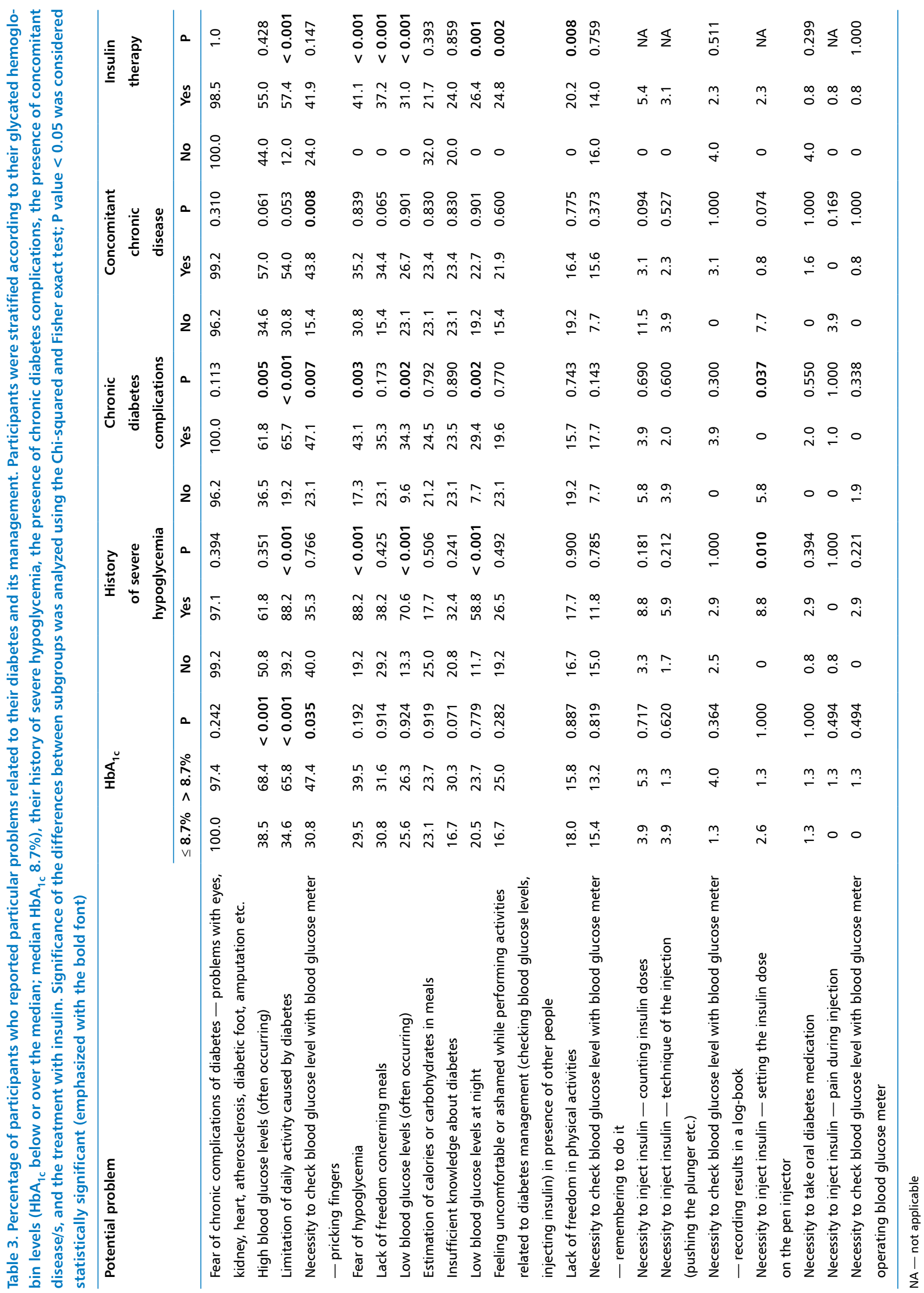


Table 4. Percentage of participants who rated needs for improvement related to diabetes and its management as non-significant and significant. Respondents rated the importance of their needs on a five level Likert-type scale: 1 - no need, 2 - little need, 3 - moderate need, 4 - big need, 5 - huge need, and answers were further grouped as indicating nonsignificant (scores 1 and 2) or significant (scores 3, 4, 5) need for improvement. Needs rated as significant by the highest percentage of participants are listed first

\begin{tabular}{|c|c|c|c|}
\hline $\begin{array}{l}\text { Needs for improvement related to diabetes } \\
\text { and its management }\end{array}$ & $\begin{array}{l}\text { Participants who } \\
\text { rated a need } \\
\text { as significant }(\%)\end{array}$ & $\begin{array}{c}\text { Participants who } \\
\text { rated a need } \\
\text { as non-significant (\%) }\end{array}$ & $\begin{array}{c}\text { Total number } \\
\text { of answers }\end{array}$ \\
\hline Glucose levels assessment without finger pricking & 98.0 & 2.0 & 154 \\
\hline $\begin{array}{l}\text { Telemedicine development to share data including doses } \\
\text { of insulin, blood glucose levels, meals etc. with a physician } \\
\text { (possibility to communicate via mobile phone, computer, } \\
\text { internet etc.) }\end{array}$ & 98.0 & 2.0 & 154 \\
\hline $\begin{array}{l}\text { Creating/improving a device, which automatically adjusts } \\
\text { insulin doses based on glucose levels (an "artificial pancreas") }\end{array}$ & 91.6 & 8.4 & 154 \\
\hline Counting calories/carbohydrates in a meal & 84.4 & 15.6 & 154 \\
\hline $\begin{array}{l}\text { Shortening time of blood glucose measurement with } \\
\text { a blood glucose meter }\end{array}$ & 83.8 & 16.2 & 154 \\
\hline Memory of insulin doses in an insulin pen & 83.0 & 17.0 & 129 \\
\hline Reminding about necessity of injecting insulin & 81.4 & 18.6 & 129 \\
\hline $\begin{array}{l}\text { Reducing pain related to pricking fingers for measurement } \\
\text { of blood glucose level }\end{array}$ & 80.5 & 19.5 & 154 \\
\hline $\begin{array}{l}\text { Mobile phone apps automatically sending glucose level data } \\
\text { to family members }\end{array}$ & 63.0 & 37.0 & 154 \\
\hline $\begin{array}{l}\text { Telemedicine development to share data including doses } \\
\text { of insulin, blood glucose levels, meals etc. } \\
\text { with family members (possibility to communicate via mobile } \\
\text { phone, computer, internet etc.) }\end{array}$ & 62.3 & 37.7 & 154 \\
\hline Relatives' help in diabetes management & 46.8 & 53.3 & 154 \\
\hline $\begin{array}{l}\text { Nurse/non-family caregiver support in diabetes management } \\
\text { at home }\end{array}$ & 28.6 & 71.4 & 154 \\
\hline
\end{tabular}

etc. (98\%). Patients would like to have a possibility to contact a diabetologist between medical appointments via: phone calls $(97.8 \%$ of patients), text messages (52.6\%), emails (35\%), or other means of electronic communication (35.8\%). Need for development of an "artificial pancreas" ("a device, which automatically provides adjusted doses of insulin based on glucose levels") was reported by $91.6 \%$, and need for counting the calories/carbohydrates amount in meals in an easy way by $84.4 \%$ of participants. Other needs claimed as significant by more than $50 \%$ of participants were: shorter time of blood glucose measurement with blood glucose meter, memory of insulin doses in insulin pens, reminding about necessity of injecting insulin, reducing pain related to pricking fingers for measurement of blood glucose levels, mobile phone apps automatically sending glucose level data to family members, telemedicine development to share data related to diabetes management with family members (possibility to communicate via mobile phone, computer, internet).

Needs for telemedicine development (to improve communication with family members to share diabetes therapy-related information with them), "artificial pancreas" development, relatives' help in diabetes management and for a nurse/non-family caregiver support in diabetes management at home (participants generally did not have such support at the time of the study) were more frequently reported by patients with $\mathrm{HbA}_{1 \mathrm{c}}$ above median (compared to these with $\mathrm{HbA}_{1 \mathrm{c}}$ below median), positive history of severe hypoglycemia (compared to these without severe hypoglycemia history), chronic diabetes complications, or concomitant chronic diseases (compared to these without comorbidities), and by those who were on insulin therapy (compared to participants treated only with oral hypoglycemic agents) (Table 5). There was 


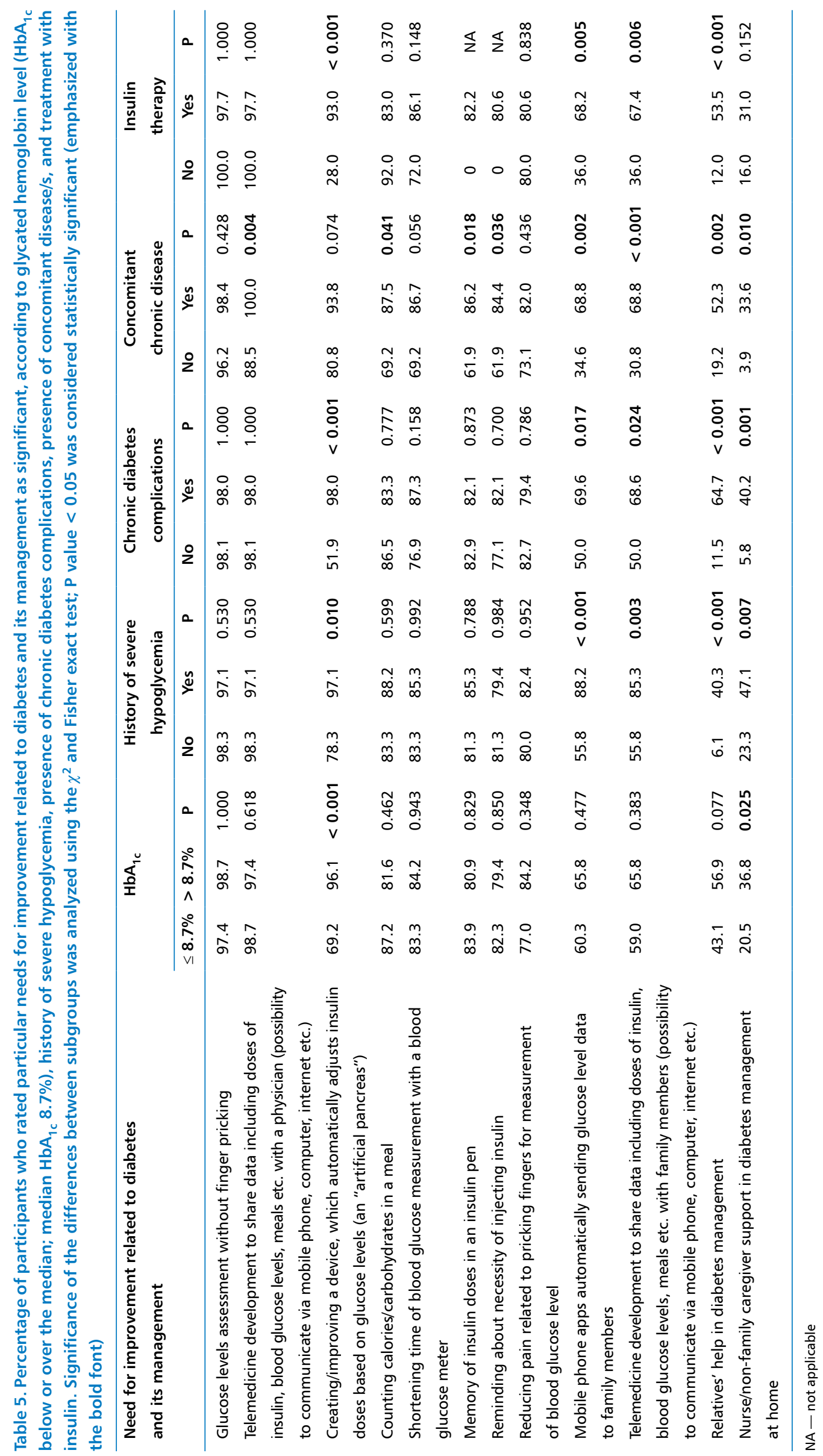


a positive correlation between longer diabetes duration and perceiving technological development in diabetes management as more significant $(\rho=0.50)$. However, the correlations with diabetes duration were negative for patients' need for enabling them a contact with the diabetologist between medical appointments $(\rho=-0.55$ for e-mail contact, $\rho=-0.47$ for text messages and $\rho=-0.56$ for contact via other electronic media). Moreover patients with diabetes duration longer than median for the total group (over 12 years) reported significantly more frequently $(P<0.05)$ compared to patients with shorter diabetes duration a significant need for development in telemedicine (67\% vs. $33 \%)$, mobile apps use $(66 \%$ vs. $33 \%)$ and development of an "artificial pancreas" (61\% vs. 22\%), while similarly wishing more frequently for a nurse support at home (77\% vs. $45 \%)$.

In the total group advancements in diabetes technologies which help patients with type 2 diabetes and their families in daily management of the disease were perceived by $0.6 \%$ of participants as huge, by $5.8 \%$ as big, by $47.4 \%$ as moderate, by $29.9 \%$ as small, and $16.3 \%$ of responders did not notice any development in this field.

\section{Discussion}

This study was focused on diabetes and diabetes management-related issues which were challenging for persons with type 2 diabetes and could be targeted by existing and emerging technological solutions. Studies describing these aspects are sparse, some included small groups of patients, and in others study groups were heterogeneous, without well-defined diabetes therapy used by participants. Our study included a relatively large and homogeneous group of patients with type 2 diabetes who used either oral hypoglycemic medication and/or insulin.

We found that $50 \%$ of participants reported diabetes-related limitations in daily activity (Table 2). Results of Rekeneire's et al. cross-sectional analysis of 3075 well-functioning older individuals from the USA, aged 70-79, comparing limitations in everyday activity between participants with and without diabetes were consistent with our study, since they observed such limitations in 53\% of patients with diabetes [15]. Moreover, they have shown that suboptimal glycemic control (higher $\mathrm{HbA}_{1 \mathrm{c}}$ ) and longer diabetes duration played an important role in the disablement process. This is also in agreement with our results as we have found that frequency of limitations was higher in patients with higher $\mathrm{HbA}_{1 \mathrm{c}}$ (65.8\% in a subgroup with $\mathrm{HbA}_{1 \mathrm{c}} \geq 8.7 \%$ vs. $34.6 \%$ in a subgroup with $\mathrm{HbA}_{1 \mathrm{c}}$ $<8.7 \%$, i.e. below median, $\mathrm{P}<0.001)$. The presented study group was age-diverse, while de Rekeneire et al. [15] included only elderly population. Moreover, in our study most patients had chronic complications $(66.2 \%)$ or other comorbidities (83\%) and all were treated with oral hypoglycemic agents and/or insulin, while in their group only $64.4 \%$ of participants used any hypoglycemic medication. The percentage of daily limitation occurrence was similar even though our study population was younger $(65.6 \pm 8.3$ years vs. $73.6 \pm$ 2.9 years). Such results suggest that the need for a more intensive diabetes therapy goes along with comorbidities and with a higher risk of daily activity limitation. In the Medical Outcomes Study Short Form 36 - Item Health Survey (SF36) that included 694 patients with type 2 diabetes from two clinics in Iran, limitation of daily activity was observed in $67.5 \%$ of participants but, unlike in our survey, the authors did not establish whether disability was related to diabetes and the type of its therapy [16]. Adding to previous reports our data demonstrated that for multiple aspects there exists a dependency between diabetes duration and the perception of problems experienced by the patients. Overall, patients with longer diabetes duration state that they deal with more problems, the most evident being fear of chronic diabetes complications, diabetes limiting patient's daily activities and dependence on family members' help.

Papaspurou et al. [17] described fears and needs of persons with type 2 diabetes in a qualitative study, using interpretative phenomenological approach. Fears for chronic diabetes complications claimed by participants of their study overlapped fears declared by vast majority of our study group (98.7\%). Moreover, they indicated fears for familial predisposition to the disease, deprivation and stigmatization which were not considered in our research. Needs of patients with diabetes reported in that study were partly similar to our results, in particular need for easier communication with medical teams. Grammes et al. [18] studied 64 adults with type 2 diabetes on insulin therapy with a questionnaire identifying potential reasons of patient fear and they found that $46.9 \%$ of participants dealt with fear of hypoglycemia, and this percentage was even higher than in our group (34.4\%).

Patients' needs concerning new technologies identified in the present survey focused primarily on improvement of glucose concentration measurements (without finger pricking), easier or more frequent communication with a physician (in Poland it is usually a doctor who coordinates diabetes care however this need represents the willingness to contact either the doctor or other specialist from the diabetes care team, e.g. a nurse), support in insulin therapy (automation 
of insulin dosing, reminding about insulin injections, memorizing insulin doses) and food counting. Studies assessing needs or expectations of patients with type 2 diabetes towards new technologies as well as randomized clinical trials evaluating mHealth interventions have focused mostly on telemedicine solutions that used short-text-messages, telephone calls and mobile apps supporting self-monitoring of blood glucose or on software supporting CGM (e.g. FGM) systems use [19-21]. Watterson et al. [19] proved that many type 2 diabetes patients admitted that a specialized textmessaging program supported them in their daily live with diabetes: $78 \%$ of respondents answered that they learned useful information from text messages, and text messages helped $89 \%$ of them to better manage diabetes [19]. These results are in accordance with ours, as $52.6 \%$ of our respondents wanted to have a possibility to contact a diabetologist between medical appointments via text messages.

In our analysis the study group was well defined (age, sex, BMI, diabetes duration, type of diabetes therapy, presence of chronic complications of diabetes, history of severe hypoglycemia, presence of concomitant chronic diseases). The majority of participants had chronic diabetes complications or concomitant chronic diseases, almost one in four had a history of severe hypoglycemia. The reported needs for development and introduction of new technologies targeting different aspects of diabetes management was high since 95\% of the total study group indicated the need to check glucose levels without pricking fingers and for sharing diabetes therapy-related data with the therapeutic team (Table 4). Possibly the considerable health burden, which implies limitations in daily activity, contributed to a strong demand for improvement as patients with $\mathrm{HbA}_{1 \mathrm{c}}$ above median, positive severe hypoglycemia history, presence of chronic diabetes complications, presence of a concomitant chronic disease and patients on insulin therapy, reported needs for telemedicine development (improvement of diabetes management related communication with family members) and for "artificial pancreas" development more frequently than patients without these health problems (Table 5). Our observation is however discordant with the results of a study that included patients from T1DM Exchange registry, as patients with type 1 diabetes with the most positive attitudes toward diabetes technology (frequent pump and CGM use) had the lowest $\mathrm{HbA}_{1 \mathrm{c}}$ compared to persons with very low new device uptake [22]. This may imply that disease trajectories of patients with type 2 diabetes who are willing to use new technologies are different from those of patients with type 1 diabetes who embrace new diabetes devices. Our data demon- strate that for multiple aspects there exists a dependency between diabetes duration and the perception of problems experienced by the patients. Overall patients with longer diabets duration state that they deal with more problems. Moreover, in our study patients with longer diabetes duration seemed to be less interested in telemedicine contact with the diabetes team, albeit, at the same time they more frequently claimed to perceive technological developments. Furthermore, it is worth emphasizing that with longer disease duration there is a higher need for family members or nurse help, while costs become a more significant burden.

Homogeneity of our sample may be viewed as a limitation of the study, as criterion of including only patients who required hypoglycemic medication (insulin or oral hypoglycemic agents) skew the study group characteristics to higher morbidity, not representative for the general population of persons with type 2 diabetes. Another limitation is that the questionnaire was piloted only in a few patients. However this allowed the decision to be made that in case of the surveyed group an investigator filled in the questionnaire during an interview with participants, and thanks to this the survey was easier to carry out among patients and it was more reliable. Additionally, to minimize the pollster bias, the same investigator interviewed all patients.

A favorable lesson learned from our survey is that certain needs expressed by persons with type 2 diabetes can be addressed, as many technological solutions claimed by them already exist (e.g. CGM systems, insulin pens memorizing insulin doses, artificial pancreas systems and tele-diabetological care tools) [23]. Surprisingly almost half (46\%) of participants perceived the recent advancement in diabetes technology as only small or none. Such observation reveals the need to unfold the high potential of digital technologies by adapting them to expectations of persons with type 2 diabetes in the context of value-based diabetes management regimens. This requires elaboration of reasonable reimbursement strategies which can be facilitated by open collaboration within the framework of public-private partnerships such as the European Institute of Innovation and Technology (EIT) Health (www.eithealth.eu), the JDRF, and the KOMIT (https://komit-nrw.de/) or other national institutions which secure an early involvement of all relevant stakeholder groups, including patients, healthcare system and payers.

\section{Conclusions}

Diabetes technologies that meet many of the needs of patients with type 2 diabetes already exist and many others will be probably available in the foreseeable future. This study demonstrated that needs of subgroups 
of patients with comorbidities or other concomitant health burdens are in several aspects different than needs of patients with less health burdens and this heterogeneity must be taken into consideration in ongoing research on new diabetes technologies. Such strategy should enhance acceptance of existing and new solutions in daily diabetes management by people with comorbidities. Overall, implementation of several existing solutions that diabetes patients claim for, might be challenging owing to economic or organizational factors (e.g. use of CGM systems by patients who don't have reimbursement for them), but others, relatively low-cost approaches can be easily promoted. For instance, the majority of population, also elderly, own smartphones or even computers, however, many are probably either not aware of the existence of medical applications supporting diabetes management (e.g. facilitating calories counting, meal planning, sharing glucose data with health personnel) or they do not know how to take advantage of them. Taking into account needs and expectations of people with type 2 diabetes identified in this study we conclude that encouraging healthcare professionals to promote innovations should be coupled with easing patients' access to modern devices through wider reimbursement or insurers co-payment for them (e.g. for CGM systems). Based on the gathered information, we conclude that the challenge pertains to both, the implementation of the right technological solutions fulfilling needs of particular groups of patients, and to helping them to embrace novelties into their daily lives.

\section{Acknowledgements}

We thank the participants and the staff of the Department of Internal Diseases and Diabetology, Medical University of Lodz and "Nowa" Outpatient Clinic in Lodz, Poland for making this study possible. We thank the European Institute of Innovation and Technology consortium (www.eithealth.eu) for making this study possible. This study was supported by the EIT Health project "CLOSE - Automated glucose control at home for people with chronic disease" (https://eit-health.de/ en/close/).

\section{Conflict of interest}

The authors have no conflict of interest to disclose.

\section{REFERENCES}

1. Ogurtsova K, da Rocha Fernandes JD, Huang Y, et al. IDF Diabetes Atlas: Global estimates for the prevalence of diabetes for 2015 and 2040. Diabetes Res Clin Pract. 2017; 128: 40-50, doi: 10.1016/j.diabres.2017.03.024, indexed in Pubmed: 28437734.
2. Rubin R, Peyrot M. Quality of life and diabetes. Diabetes/Metabolism Research and Reviews. 1999; 15(3): 205-218, doi: 10.1002/ (sici)1520-7560(199905/06)15:3<205::aid-dmrr29>3.0.co;2-o.

3. Arnolds S, Heckermann S, Koch C, et al. How do patients' preferences compare to the present spectrum of diabetes research? Exp Clin Endocrinol Diabetes. 2013; 121(1): 60-63, doi: 10.1055/s0032-1323776, indexed in Pubmed: 22972031.

4. Arnolds S, Heckermann S, Heise T, et al. Spectrum of diabetes research does not reflect patients' scientific preferences: a longitudinal evaluation of diabetes research areas 2010-2013 vs. a cross-sectional survey in patients with diabetes. Exp Clin Endocrinol Diabetes. 2015; 123(5): 299-302, doi: 10.1055/s0034-1398591, indexed in Pubmed: 25658664.

5. Barber S, French C, Matthews R, et al. The role of patients and carers in diffusing a health-care innovation: A case study of "My Medication Passport". Health Expect. 2019; 22(4): 676-687, doi: 10.1111/hex.12893, indexed in Pubmed: 31131523.

6. Bailey TS, Walsh J, Stone JY. Emerging technologies for diabetes care. Diabetes Technol Ther. 2018; 20(S2): S278-S284, doi: 10.1089/dia.2018.0115, indexed in Pubmed: 29916738.

7. Gonder-Frederick LA, Shepard JA, Grabman JH, et al. Psychology, technology, and diabetes management. Am Psychol. 2016; 71(7): 577-589, doi: 10.1037/a0040383, indexed in Pubmed: 27690486.

8. Fatehi F, Menon A, Bird D. Diabetes care in the digital era: a synoptic overview. Curr Diab Rep. 2018; 18(7): 38, doi: 10.1007/ s11892-018-1013-5, indexed in Pubmed: 29748905.

9. Cefalu WT, Tamborlane WV. The artificial pancreas: are we there yet? Diabetes Care. 2014; 37(5): 1182-1183, doi: 10.2337/dc140491, indexed in Pubmed: 24757224.

10. Schliess $F$, Heise T, Benesch C, et al. Artificial pancreas systems for people with type 2 diabetes: conception and design of the European CLOSE Project. J Diabetes Sci Technol. 2019; 13(2): 261-267, doi: 10.1177/1932296818803588, indexed in Pubmed: 30241444 .

11. Benhamou PY, Franc S, Reznik Y, et al. Closed-loop insulin delivery in adults with type 1 diabetes in real-life conditions: a 12-week multicentre, open-label randomised controlled crossover trial. The Lancet Digital Health. 2019; 1(1): e17-e25, doi: 10.1016/ s2589-7500(19)30003-2.

12. Park C, Le QA. The Effectiveness of continuous glucose monitoring in patients with type 2 diabetes: a systematic review of literature and meta-analysis. Diabetes Technol Ther. 2018; 20(9): 613-621, doi: 10.1089/dia.2018.0177, indexed in Pubmed: 30095980

13. Bally $L$, Thabit $H$, Hartnell $S$, et al. Closed-loop insulin delivery for glycemic control in noncritical care. N Engl J Med. 2018; 379(6): 547-556, doi: 10.1056/NEJMoa1805233, indexed in Pubmed: 29940126.

14. Reznik Y, Cohen O, Aronson R, et al. Insulin pump treatment compared with multiple daily injections for treatment of type 2 diabetes (OpT2mise): a randomised open-label controlled trial. The Lancet. 2014; 384(9950): 1265-1272, doi: 10.1016/s01406736(14)61037-0.

15. De Rekeneire N, Resnick HE, Schwartz AV, et al. Health, Aging, and Body Composition study. Diabetes is associated with subclinical functional limitation in nondisabled older individuals: the Health, Aging, and Body Composition study. Diabetes Care. 2003. 26(12): 3257-3263, doi: 10.2337/diacare.26.12.3257, indexed in Pubmed: 14633811.

16. Faraji Gavgani L, Sarbakhsh P, Asghari Jafarabadi M, et al. Identifying factors associated with functional limitation among diabetic patients in Northwest of Iran: application of the generalized additive model. Int J Endocrinol Metab. 2018; 16(2): e12757, doi: 10.5812/ijem.12757, indexed in Pubmed: 30008756.

17. Papaspurou M, Laschou VC, Partsiopoulou $P$, et al. Fears and health needs of patients with diabetes: a qualitative research in rural population. Med Arch. 2015; 69(3): 190-195, doi: 10.5455/ medarh.2015.69.190-195, indexed in Pubmed: 26261390. 
18. Grammes J, Stock W, Mann CG, et al. Focus group study to identify the central facets of fear of hypoglycaemia in people with Type 2 diabetes mellitus. Diabet Med. 2017; 34(12): 1765-1772, doi: 10.1111/dme.13506, indexed in Pubmed: 28856721.

19. Watterson JL, Rodriguez HP, Shortell SM, et al. Improved diabetes care management through a text-message intervention for low-income patients: mixed-methods pilot study. JMIR Diabetes. 2018; 3(4): e15, doi: 10.2196/diabetes.8645, indexed in Pubmed: 30377141.

20. Dobson $R$, Whittaker $R$, Jiang $Y$, et al. Effectiveness of text message based, diabetes self management support programme (SMS4BG): two arm, parallel randomised controlled trial. BMJ. 2018; 361: k1959, doi: 10.1136/bmj.k1959, indexed in Pubmed: 29773539.
21. Shan R, Sarkar S, Martin SS. Digital health technology and mobile devices for the management of diabetes mellitus: state of the art. Diabetologia. 2019; 62(6): 877-887, doi: 10.1007/s00125-0194864-7, indexed in Pubmed: 30963188.

22. Tanenbaum ML, Adams RN, Iturralde $E$, et al. From wary wearers to d-embracers: personas of readiness to use diabetes devices. J Diabetes Sci Technol. 2018; 12(6): 1101-1107, doi: 10.1177/1932296818793756, indexed in Pubmed: 30132692.

23. Kempf K, Altpeter B, Berger J, et al. Efficacy of the Telemedical lifestyle intervention Program TeLiPro in advanced stages of type 2 diabetes: a randomized controlled trial. Diabetes Care. 2017; 40(7): 863-871, doi: 10.2337/dc17-0303, indexed in Pubmed: 28500214. 